\title{
Diabetes May Influence Blood Pressure on Antihypertensive Drug
}

\section{Hiroshi Bando*}

Medical Research, Tokushima University, Tokushima, Japan

Keywords: Metabolic syndrome (Met-S); Hypertension; Antihypertensive drug; Type 2 diabetes mellitus (T2DM); Diabetic neuropathy

\section{Commentary}

As to metabolic syndrome (Met-S), the frequency of hypertension and diabetes increases with the progress of arteriosclerosis. Its pathophysiological mechanism also involves the control of the nervous system. In other words, regarding the adjustment of blood pressure in humans, the blood pressure will fluctuate by adjusting mechanism of the nervous system, corresponding to the body position, movement, exercise and psycho-psychiatric changes in various situations. There is no problem in normal persons concerning these regulatory mechanisms. However, in the patients associated with hypertension or previous stroke, the mechanism for instantaneously regulating blood pressure has been impaired. Therefore, blood pressure may rise or fall suddenly in such patients.

In this article, I would like to describe recent various findings related to Met-S, hypertension and diabetes and introduce our study results concerning discontinuation of antihypertensive drug. Met-S was originated and studied from syndrome X in 1980s [1,2]. Since then several kinds of diagnostic criteria have been found in each association and country [3]. In recent years, prevalence of Met-S has been gradually elevated for decades, including medical, social and economic problems [4-6]. This tendency has been spread in every country [7].

Met-S has been also defined as a cluster of interconnected metabolic abnormalities accompanied by glucose metabolism. They also include dyslipidemia, elevated blood pressure and central obesity [8].

According to lots of reports so far, Met-S increases the risk of death from all causes including type 2 diabetes and cardiovascular disease [9]. Furthermore, Met-S is also associated with other co-morbidities including thrombosis and pro-inflammatory conditions, non-alcoholic steatohepatitis and reproductive disorders and certain types of cancer [10].

Hypertension included in Met-S has been called 'silent killer'. Without any symptoms, it always exacerbates arteriosclerosis for years. The frequency is high in each country worldwide and its treatment, care and prevention for hypertension would be important from adulthood to middle-aged and elderly. Therefore, in recent years, various guidelines have been presented in each country.

There have been several guidelines for hypertension and heart disease, in Japan [11], in North American region [12,13] and in European countries [14,15]. In addition, some related guidelines for patients with lipid and obesity are found $[16,17]$ and guidelines for young generation and the elderly have been also presented in recent years [18,19]. In the future, treatment and management for hypertension would be continued for comprehensively utilizing these guidelines for patients with metabolic syndrome suffering from some diseases.

To investigate the treatment of many patients, two dimensional viewpoints of warp and weft are important, which is longitudinal thread and transvers thread, respectively. The former is medical treatments on hypertension for several decades. On contrast, the latter is to examine and evaluate various data in epidemiological way.
There are some examples as follows: how many people are already treating with hypertension, how many people have hypertension tendency in preclinical stage, how much extent does certain antihypertensive drug lower the blood pressure in the relevant population, what kind of treatment or care should be done for hypertension in a certain country, what kind of beneficial outcome will be expected by this policy and so on [20]. Among them, in addition to drug administration, it will be necessary to investigate and examine the contents and effects of "non-drug therapy" for hypertension [21].

Non-medicinal therapy usually means our lifestyle, including meal, exercise, rest, alcohol and smoking. There has been 2017 High Blood Pressure Clinical Practice Guideline, which is a Report of the American College of Cardiology/American Heart Association Task Force on Clinical Practice Guidelines [13]. It showed six aspects for recommendations for non-pharmacological interventions at the level of 1-A.

These are summarized to weight loss [22], a heart-healthy diet such as the DASH (Dietary Approaches to Stop Hypertension) diet [21], sodium reduction [23], potassium supplementation [24], increased physical activity [25] and reduction in alcohol consumption [26].

The author and colleagues investigated lot of hypertensive cases who could discontinue the administration of anti-hypertensive drugs [27]. We have thousands of cases of hypertension in a year, in which $4.6 \%-6.1 \%$ cases could stop antihypertensive drugs in a few years. For example, 50 cases with each 25 in male and female were studied in detail. There were family histories of hypertension 33 cases (66\%) in women, smoking $76 \%$ in men, alcohol consumption $60 \%$ in men, $42 \%$ for dyslipidemia $42 \%$ and type 2 diabetes mellitus (T2DM) 12\%. The frequency of $12 \%$ may be lower than expected, in comparison with others.

For these results, some possible reasons were speculated. Diabetic status can cause microangiopathy and macroangiopathy associated with neuropathy including peripheral and autonomic regulation. Then, hypertensive patients with diabetes may be rather difficult to discontinue antihypertensive drugs because of impaired mechanism of neural and vascular regulation of blood vessels. Probably, the cases with successful discontinuation of drug may have several necessary factors with light hypertension, regular life, limited status of obesity, diabetes and other influential impairments.

Moreover, discontinuation of antihypertensive treatment is affect by a large number of factors in a real life setting [28]. They include type of antihypertensive treatment, co-treatments, clinical conditions, social and environmental factors where the patient lives.

${ }^{*}$ Corresponding author: Hiroshi Bando, MD, PhD, FACP, Medical Research, Tokushima University, Nakashowa 1-61, Tokushima 770-0943, Japan, Tel: +819031872485; E-mail: pianomed@bronze.ocn.ne.jp

Received May 06, 2018; Accepted May 16, 2018; Published May 23, 2018

Citation: Bando H (2018) Diabetes May Influence Blood Pressure on Antihypertensive Drug. Int J Neurorehabilitation 5: 320. doi: 10.4172/23760281.1000320

Copyright: ( $) 2018$ Bando $\mathrm{H}$. This is an open-access article distributed under the terms of the Creative Commons Attribution License, which permits unrestricted use, distribution, and reproduction in any medium, provided the original author and source are credited. 
As for the diabetes guidelines, changes have been observed recently. American Diabetes Association (ADA) followed the joint algorithm of European Diabetes Society (EASD) 2012 [29] until 2017 [30]. For example, metformin is used as an initiator, and various drugs are listed as horizontal lines.

On contrast, recommendations were changed in the 2018 edition [31]. Metformin is used as a single agent. When HbAlc is $9 \%$ or more, 2 agents with metformin+other drug are used. When $\mathrm{HbAlc}$ is $10 \%$ or more, 3 agents with metformin+other drugs or insulin therapy would be considered.

Furthermore, American College of Physicians (ACP) showed official comments concerning diabetes in 2017 [32]. It has surprising recommendations with a paradigm change. There was Statement 2, in which clinicians should set the management goal for HbAlc in most T2DM patients to be $7 \%$ or more and less than $8 \%$.

Consequently, we can find large paradigm changes in also diabetes field. We would continue medical practice with attention to the management of hypertension and diabetes using adequate and satisfactory guideline as well as respecting QOL/ADL and psychological desire of the patients from now.

\section{References}

1. Reaven GM (1995) Pathophysiology of insulin resistance in human disease Physiol Rev 75: 473-486.

2. Reaven GM (1988) Role of insulin resistance in human disease. Diabetes 37 $1595-1607$.

3. Sarafidis PA, Nilsson PM (2006) The metabolic syndrome: A glance at its history. J Hypertens 24: 621-626.

4. McGill AT (2014) Past and future corollaries of theories on causes of metabolic syndrome and obesity related co-morbidities part 2: A composite unifying theory review of human-specific co-adaptations to brain energy consumption. Arch Public Health 72: 31.

5. Suh S, Lee MK (2014) Metabolic syndrome and cardiovascular diseases in Korea. J Atheroscler Thromb 21: S31-35.

6. Agirbasli M, Tanrikulu AM, Berenson GS (2016) Metabolic syndrome: Bridging the gap from childhood to adulthood. Cardiovasc Ther 34: 30-36.

7. Ansarimoghaddam A, Adineh HA, Zareban I, Iranpour S, Hossein ZA, et al. (2018) Prevalence of metabolic syndrome in Middle-East countries: Metaanalysis of cross-sectional studies. Diabetes Metab Syndr 12: 195-201.

8. Amihaesei IC, Chelaru L (2014) Metabolic syndrome a widespread threatening condition; risk factors, diagnostic criteria, therapeutic options, prevention and controversies: An overview. Rev Med Chir Soc Med Nat lasi 118: 896-900.

9. Cornier MA, Dabelea D, Hernandez TL, Lindstrom RC, Steig AJ, et al. (2008) The metabolic syndrome. Endocr Rev 29: 777-822.

10. O'Neill S, O'Driscoll L (2015) Metabolic syndrome: A closer look at the growing epidemic and its associated pathologies. Obes Rev 16: 1-12.

11. The Task Force for the management of Hypertension of the Japanese Society of Hypertension (JSH) and JSH (2014) Guideline for the management of hypertension 2014

12. Goff DC, Lloyd-Jones DM, Bennett G, Coady S, D'Agostino RB, et al. (2014) 2013 ACC/AHA guideline on the assessment of cardiovascular risk. A report of the American college of cardiology/American heart association task force on practice guidelines circulation. Circulation 129: S49-S73.

13. Whelton PK, Carey RM, Aronow WS, Casey DE, Collins KJ, et al. (2017) 2017 ACC/AHA/AAPA/ABC/ACPM/AGS/APhA/ASH/ASPC/NMA/PCNA Guideline for the prevention, detection, evaluation, and management of high blood pressure in adults 2017 high blood pressure clinical practice guideline. A report of the American college of cardiology/American heart association task force on clinical practice guidelines. Hypertension.
14. Perk J, De Backer G, Gohlke H, Graham I, Reiner Z, et al. (2012) European association for cardiovascular prevention \& rehabilitation (EACPR); ESC committee for practice guidelines (CPG). European guidelines on cardiovascular disease prevention in clinical practice (version 2012). The fifth joint task force of the european society of cardiology and other societies on cardiovascular disease prevention in clinical practice. Eur Heart J 33: 1635-1701.

15. The task force for the management of arterial hypertension of the European society of hypertension (ESH) and of the European society of cardiology (ESC) (2013) $2013 \mathrm{ESH} / \mathrm{ESC}$ guidelines for the management of arterial hypertension. European Heart Journal 34: 2159-219.

16. Jensen MD, Ryan DH, Apovian CM, Ard JD, Comuzzie AG, et al. (2014) 2013 AHA/ACC/TOS guideline for the management of overweight and obesity in adults: A report of the American college of cardiology/American heart association task force on practice guidelines and the obesity society. Circulation 129: S102-138.

17. Catapano AL, Graham I, Backer GD, Wiklund O, Chapman MJ, et al. (2016) 2016 ESC/EAS guidelines for the management of dyslipidaemias: The task force for the management of dyslipidaemias of the European society of cardiology (ESC) and European atherosclerosis society (EAS) developed with the special contribution of the European association for cardiovascular prevention \& rehabilitation (EACPR). Atherosclerosis 253: 281-344.

18. The Japan Geriatrics Society (2017) The Japan geriatrics society guidelines for the management of elderly hypertension 2017 . J Jap Geriat Soc 54: 236-237.

19. Lurbe E, Agabiti-Rosei E, Cruickshank JK, Dominiczak A, Erdine S, et al. (2016) 2016 European society of hypertension guidelines for the management of high blood pressure in children and adolescents. J Hypertens 34: 1887-1920.

20. Cook NR, Cutler JA, Obarzanek E, Buring JE, Rexrode KM, et al. (2007) Long term effects of dietary sodium reduction on cardiovascular disease outcomes: Observational follow-up of the trials of hypertension prevention (TOHP). BMJ 334: 885-888.

21. Whelton PK (2015) The elusiveness of population-wide high blood pressure control. Annu Rev Public Health 36: 109-130.

22. Neter JE, Stam BE, Kok FJ, Grobbee DE, Geleijnse JM (2003) Influence of weight reduction on blood pressure: A meta-analysis of randomized controlled trials. Hypertension 42: 878-884.

23. Mozaffarian D, Fahimi S, Singh GM (2014) Global sodium consumption and death from cardiovascular causes. N Engl J Med 371: 624-634.

24. Dietary Guidelines Advisory Committee (2015) Dietary guidelines for Americans 2015-2020. Washington, DC: Department of health and human services (U.S.) Department of agriculture (U.S).

25. Carlson DJ, Dieberg G, Hess NC, Millar PJ, Smart NA (2014) Isometric exercise training for blood pressure management: A systematic review and meta-analysis. Mayo Clin Proc 89: 327-334.

26. Roerecke M, Kaczorowski J, Tobe SW, Gmel G, Hasan OSM, et al. (2017) The effect of a reduction in alcohol consumption on blood pressure: A systematic review and meta-analysis. Lancet Public Health 2: e108-120.

27. Bando M, Fujiwara I, Imamura Y, Takeuchi Y, Hayami E, et al. (2018) Lifestyle habits adjustment for hypertension and discontinuation of antihypertensive agents. J Hypertens 7: 249

28. Mancia G, Zambon A, Soranna D, Merlino L, Corrao G (2014) Factors involved in the discontinuation of antihypertensive drug therapy: an analysis from real life data. J Hypertens 32: 1708-1715.

29. Rodbard HW, Jellinger PS (2012) Comment on: Inzucchi et al. Management of hyperglycemia in type 2 diabetes: A patient-centered approach. Position statement of the American Diabetes Association (ADA) and the European Association for the Study of Diabetes (EASD). Diabetes Care 35:1364-1379. Diabetes Care 35: e71.

30. American Diabetes Association (2017) Pharmacologic approaches to glycemic treatment. Diabetes Care 40: S64-S74.

31. American Diabetes Association (2018) Pharmacologic approaches to glycemic treatment: Standards of medical care in diabetes, 2018. Diabetes Care 41 S73-S85.

32. American College of Physicians (2017) Clinical guidelines and recommendations. 